\title{
Up-regulation of matrix metalloproteinases- 9 in the kidneys of diabetic rats and the association with neutrophil gelatinase- associated lipocalin
}

\author{
Huayu Yang ${ }^{1}$, Haiping Chen ${ }^{1 *}$, Fenghua Liu ${ }^{2}$ and Qing Ma ${ }^{1}$
}

\begin{abstract}
Background: Matrix metalloproteinases-9 (MMP-9) can regulate extracellular matrix deposition in diabetic glomerular injury. However, it remains unknown whether MMP-9 is involved in the renal tubular injury. Meanwhile, neutrophil gelatinase-associated lipocalin (NGAL), defined as a biomarker of proximal tubular injury, may influence MMP-9 by forming the MMP-9/NGAL complex. The aim of this study was to investigate MMP-9 expression in proximal renal tubules and the relationship of MMP-9 and NGAL in diabetic rat model treated with Valsartan.

Methods: Sprague Dawley rats were randomly divided into three groups: Diabetic group, Control group, and Treated group. The diabetic rat model was established by injection of streptozotocin. Related indexes were measured at the end of the 2 nd, 4th, 8th and 12th week post-modeling.

Results: In diabetic groups, the concentrations of MMP-9 markedly increased in the serum and urine of rats in the early stage, even before the appearance of pathological albuminuria. Markedly elevated MMP-9/NGAL complex concentrations were also tested in diabetic groups. Western blot and QPCR tests confirmed that MMP-9 expression levels in the proximal renal tubular epithelial cells of diabetic rats were significantly higher than in control groups $(P<0.05)$. Correlation analysis showed that MMP-9 was positively correlated with NGAL at both protein and gene expression levels. In addition, Valsartan observably reduced tubular injury as well as MMP-9 expression in diabetic rats.

Conclusions: In diabetic kidney injury, the expression of MMP-9 in the proximal renal tubular epithelial cells was significantly increased. Besides, a positive correlation was found between MMP-9 and NGAL expression, along with high levels of MMP-9/NGAL complex, which indicated that NGAL might participate in the regulation of MMP-9 expression. The administration of Valsartan may reduce this effect.
\end{abstract}

Keywords: Diabetic rats, Matrix Metalloproteinases-9, Neutrophil Gelatinase-associated Lipocalin

\footnotetext{
* Correspondence: chp3@sina.com

'Division of Geriatrics, Medical and Health Care Center, Beijing Friendship Hospital, Capital Medical University, No. 95, Yong'an Road, Xicheng District, 100050 Beijing, People's Republic of China

Full list of author information is available at the end of the article
}

(C) The Author(s). 2021 Open Access This article is licensed under a Creative Commons Attribution 4.0 International License, which permits use, sharing, adaptation, distribution and reproduction in any medium or format, as long as you give appropriate credit to the original author(s) and the source, provide a link to the Creative Commons licence, and indicate if changes were made. The images or other third party material in this article are included in the article's Creative Commons licence, unless indicated otherwise in a credit line to the material. If material is not included in the article's Creative Commons licence and your intended use is not permitted by statutory regulation or exceeds the permitted use, you will need to obtain permission directly from the copyright holder. To view a copy of this licence, visit http://creativecommons.org/licenses/by/4.0/. The Creative Commons Public Domain Dedication waiver (http://creativecommons.org/publicdomain/zero/1.0/) applies to the data made available in this article, unless otherwise stated in a credit line to the data. 


\section{Background}

Tubular damage has a pivotal role in the progression of diabetic nephropathy (DN). Our previous study discovered that proximal tubular injury appears before the appearance of pathological proteinuria in the early stage of $\mathrm{DN}$, thus suggesting that tubular lesions occur earlier than glomerular lesions [1]. With the evolvement of DN, the tubular lesions severely aggravate the decline of renal function.

Matrix metalloproteinases (MMPs), belonging to a family of $\mathrm{Zn}^{2+}$ - dependent and $\mathrm{Ca}^{2+}$-dependent endopeptidases, are abnormally expressed in various kidney diseases. Previous studies have confirmed that matrix metalloproteinase-9 (MMP-9) can regulate extracellular matrix (ECM) degradation during renal fibrosis [2, 3]. In addition, high expression of MMP-9 can induce epithelial-mesenchymal transformation (EMT) in tubular cells, which may be another mechanism for inducing renal fibrosis [4, 5]. Mice lacking matrix MMP-9 gene have been shown to have reduced disruption of the tubular basement membrane and expression of fibronectin, as well as deposition of total tissue collagen [6]. Contrary, elevated expression of MMP-9 in DM has been shown to directly stimulate the secretion of activated growth factors, such as TNF- $\alpha$, IL- $1 \beta$ and VEGF, leading to renal injury $[7,8]$.

Previous studies have found abnormally expressed MMP-9 located in integral renal tissues or glomerulus in a hyperglycemic environment. However, the exact role of MMP-9 expression and activity in the diabetic kidney remains unclear.

Multiple mechanisms may be involved in the regulation of MMP-9 expression in DN. In most cells, MMP-9 enzyme activity can be regulated by some endogenous metalloprotease inhibitors known as tissue inhibitors of metalloproteinases (TIMPs). Recent reports have shown that MMP-9 activities can also be influenced by neutrophil gelatinase-associated lipocalin (NGAL). Our previous study suggested NGAL as a specific biomarker for diabetic tubular injury [1]. Some studies suggested that a formation of an MMP-9/NGAL complex can prevent MMP-9 degradation and prolong its activity $[5,9,10]$. Moreover, several clinical studies have investigated the associations of MMP-9/NGAL complex and diabetic renal injury. However, whether this binding effect exists in diabetic kidney tissue is still not well understood.

Pre-clinical studies suggested that the progression of DN was related to persistent activation of the reninangiotensin system. The standard drug treatment for the management of kidney injury involves the administration of angiotensin-converting enzyme inhibitors or angiotensin II type 1 receptor blockers (ARBs) [11, 12]. However, the detailed mechanisms of ARBs in protecting the kidneys from DN damage are not fully understood.
In this study, we investigated the MMP-9 expression in proximal renal tubules and the relationship of MMP9 and NGAL in diabetic models, as well as the effect of Valsartan on the MMP-9 expression.

\section{Materials and methods}

\section{Experimental diabetic model}

A total of 96 male adult Sprague Dawley rats (Vital River Laboratories, Beijing, China), weighting 180 -200 g were housed in an environment with a temperature of $22 \pm 1$ ${ }^{\circ} \mathrm{C}$, a relative humidity of $50 \pm 1 \%$, and a light/dark cycle of 12/12 hr and fed with food and water at libitum. All animal studies (including the mice euthanasia procedure) were done in compliance with the regulations and guidelines of Capital Medical University (Beijing, China) institutional animal care and conducted according to the AAALAC and the IACUC guidelines.

Animals were randomly divided into three groups (32 rats per group): non-diabetic control group (Group N), diabetic group (Group D), and Valsartan treated group (Group T). The diabetic model was induced by injection of STZ (60 mg/kg of body weight, Sigma, St. Louis, MO, USA) dissolved in $0.1 \mathrm{~mol} / 1$ citrate buffer ( $\mathrm{pH} 4.5$ ). Rats in the Valsartan treated group were gavaged with Valsar$\tan \left(10 \mathrm{mg} \cdot \mathrm{kg}^{-1} \cdot \mathrm{d}^{-1}\right.$ other two groups were treated with normal saline. After $72 \mathrm{~h}$ of STZ-injection, the blood glucose level was measured levels higher than $300 \mathrm{mg} / \mathrm{dl}$ indicated that the model was successfully constructed.

\section{Collection of blood and urine specimens}

Urine samples were stored in a metabolic cage for $24 \mathrm{~h}$ at the end of 2nd, 4th, 8th, and 12th week after treatment was initiated. Eight rats in each group were euthanized using $10 \%$ chloral hydrate $450 \mathrm{mg} / \mathrm{kg}$ injected into the abdominal cavity after each time point. Then, blood samples were taken from the heart. After centrifugation, the supernatant was retained for the corresponding detection. All urine and blood samples were stored at -80 ${ }^{\circ} \mathrm{C}$ and used for the study within 3 months after collection.

\section{Biochemical parameters tests}

Serum creatinine (Scr) and blood urea nitrogen (BUN) were determined respectively at the end of the 2nd, 4th, $8^{\text {th, }}$ and 12 th weeks. Urinary albumin was determined using ELISA kits (Groundwork Biotechnology Diagnostics, San Diego, CA, USA) at the same time as above. Then, the urinary albumin excretion rate (UAER) was calculated. Body weight and kidney weight of each rat were simultaneously measured in chronological order, followed by calculating the ratio of kidney weight and body weight. 


\section{ELISA assay}

The serum MMP-9 (sMMP-9), urinary MMP-9 (uMMP9), serum NGAL (sNGAL), urinary NGAL (uNGAL), serum MMP-9/NGAL complex and urinary MMP-9/ NGAL complex levels were measured using ELISA kits (Groundwork Biotechnology Diagnostics, San Diego, CA, USA).

\section{Western blot}

Proteins extracted from renal medulla were separated on $12 \%$ SDS-polyacrylamide gels and transferred to polyvinylidene difluoride membranes. After blocking with $5 \%$ skim milk, the membranes were incubated overnight at 4. $\mathrm{C}$ with primary antibodies against MMP-9 (goat polyclonal, 1:500, Santa Cruz, CA, USA) or NGAL (rabbit polyclonal, 1:5:00, Santa Cruz, CA, USA) or TIMP-1 (rabbit polyclonal, 1:5:00, Santa Cruz, CA, USA), followed by washing and incubation with secondary rabbit anti-goat IgG (1: 20,000, Santa Cruz, CA, USA) or goat anti-rabbit IgG (1: 20,000, Santa Cruz, CA, USA). The density of MMP-9, NGAL, and TIMP-1 staining were analyzed with Quantity One software.

\section{Real-time PCR}

RNA was isolated with RNA Kit (Sunbio, Beijing, China). The cDNA was conducted with a Reverse Transcription Kit (Promega M170A). Real-time PCR was performed using Bio Easy SYBR Green I Real-Time PCR Kit (Sunbio, Beijing, China) with the following sequences of primers: MMP-9 forward: 5'- GCGCCGTGGTCCCCAC TTAC - 3'; MMP-9 reverse: 5'-GCCGTCTCCGTTGC CATGCT-3'; NGAL forward: 5'-TGAACTGAAG GAGCGATTCG-3'; NGAL reverse: 5'-ATTGGTCGGT GGGAACAGA-3'; TIMP-1 forward: 5' - TAAAGCCTGT AGCTGTGCCC-3'; TIMP-1 reverse: 5'- AGCGTCGA ATCCTTTGAGCA - 3'; GAPDH forward: 5' - ACCACC CAGCCCAGCAAGGAT-3'; GAPDH reverse: 5'- GGGG CTGAGTTGGGATGGGGAC-3'. The relative quantities were assessed by the comparative $\mathrm{Ct}$ method $(2-\Delta \Delta \mathrm{Ct})$.

\section{Immunohistochemical analysis of MMP-9}

Paraffin-embedded kidney tissue slices (3 mm thickness) were deparaffinized. Then, the slices were treated with $3 \%$ hydrogen peroxide in methanol for $10 \mathrm{~min}$. Antigen retrieval was performed with citrate buffer for $5 \mathrm{~min}$ in a $100 \mathrm{C}$ water bath. The slices were then incubated with $10 \%$ goat serum for $10 \mathrm{~min}$ at room temperature, followed by incubation with anti-MMP-9 antibody (1: 500, Santa Cruz, CA, USA) at 4 C overnight. Next, the slices were incubated with horseradish peroxidase for another $30 \mathrm{~min}$. After incubation with secondary antibodies, the sites of peroxidase activity were carried out by 3, 3-diamino-benzidine tetrahydrochloride stain as a substrate, followed by hematoxylin staining. Every slide was examined MMP-9 stains in the normal and atrophic renal tubules.

\section{Statistical analysis}

All data were expressed as means \pm standard deviation (SD). Statistical analysis was performed with SPSS 19.0. Differences in variables were tested with one-way analysis of variance (ANOVA), followed by Bonferroni posthoc analysis. The Pearson correlation coefficient was performed to examine the correlations between variables. The difference was considered statistically significant when the $P$-value was $<0.05$.

\section{Results}

\section{Clinical parameters}

Table 1 shows the basic characteristics of all the rats. Diabetic rats showed a gradual increase in blood glucose, Scr, and BUN compared to a non-diabetic control group in the same period. In addition, STZ-induced diabetic rats had an obvious increase in UAER. At the end of 2nd week, there was no significant difference $(P>0.05)$ in UAER in the Valsartan-treated rats and diabetic groups; yet, the levels decreased in week 4 compared to those in diabetic rats $(p<0.05)$ (Table 1$)$.

\section{Detection of serum and urine indicators}

We detected MMP-9 concentration in blood and urine. As shown in Fig. 1a and b, the serum and urinary MMP9 in diabetic rats gradually increased after week 2 compared with non-diabetic controls. In rats treated with Valsartan, serum MMP-9 and urinary MMP-9 concentrations decreased by about 1.4 and 3.8 times, respectively at the end of the 12th week. The changes in NGAL concentration in serum and urine were similar to those of MMP-9 (Fig. 1c and d). Serum MMP-9/NGAL complex and urinary MMP-9/NGAL complex concentrations were significantly higher in the diabetic group than in the non-diabetic control group in the same period. Similarly, the levels of the above indicators significantly decreased after treatment of Valsartan (Fig. 1e and f).

\section{Protein expression of MMP-9, NGAL, and correlation analysis}

Western blot analysis revealed the expression of MMP-9 (92KD) and NGAL (23KD) protein in renal medulla extracts. Diabetes was associated with an increase in MMP-9 and NGAL expression (Fig. 2a and b). At the 12th week, MMP-9 and NGAL protein expression levels in diabetic rats respectively increased by 2.71 -fold and 1.94-fold compared to the non-diabetic control group. As shown in Fig. 2a, b and a simultaneous decrease of MMP-9 and NGAL expression was prevented by Valsartan. Correlation analysis of MMP-9 and NGAL protein 
Table 1 The characteristics of streptozotocin-induced diabetic rats at all stages

\begin{tabular}{|c|c|c|c|c|c|}
\hline Week & Group & Scr (umol/l ) & BUN (mmol/l) & UAER (ug/min) & Blood glucose \\
\hline \multirow[t]{3}{*}{ Week 2} & $\mathrm{~N}$ & $46.00 \pm 7.80$ & $7.23 \pm 1.61$ & $0.98 \pm 0.51$ & $7.18 \pm 1.98$ \\
\hline & D & $51.17 \pm 7.81^{*}$ & $12.42 \pm 3.37^{*}$ & $2.99 \pm 1.12^{*}$ & $25.93 \pm 1.49^{*}$ \\
\hline & $\mathrm{T}$ & $52.63 \pm 8.21$ & $13.05 \pm 2.65$ & $3.10 \pm 0.62^{*}$ & $21.26 \pm 0.51^{*}$ \\
\hline \multirow[t]{3}{*}{ Week 4} & $\mathrm{~N}$ & $50.33 \pm 7.15$ & $7.10 \pm 0.84$ & $0.76 \pm 0.30$ & $8.92 \pm 1.64$ \\
\hline & D & $57.43 \pm 4.86^{*}$ & $15.25 \pm 2.87^{*}$ & $4.91 \pm 0.12^{*}$ & $29.15 \pm 1.86^{*}$ \\
\hline & $\mathrm{T}$ & $54.13 \pm 3.21$ & $11.83 \pm 1.49^{* \#}$ & $4.64 \pm 0.20^{* \#}$ & $24.67 \pm 1.90^{*}$ \\
\hline \multirow[t]{3}{*}{ Week 8} & $\mathrm{~N}$ & $55.00 \pm 3.58$ & $7.88 \pm 0.66$ & $0.76 \pm 0.41$ & $8.06 \pm 2.05$ \\
\hline & D & $63.50 \pm 5.75^{*}$ & $20.10 \pm 3.64^{*}$ & $5.91 \pm 0.15^{*}$ & $28.22 \pm 2.22^{*}$ \\
\hline & $\mathrm{T}$ & $60.13 \pm 9.85$ & $18.56 \pm 8.33^{* \#}$ & $5.48 \pm 0.53^{* \#}$ & $25.79 \pm 1.83^{*}$ \\
\hline \multirow[t]{3}{*}{ Week 12} & N & $50.38 \pm 3.89$ & $7.00 \pm 0.53$ & $0.64 \pm 0.22$ & $8.37 \pm 1.69$ \\
\hline & D & $64.88 \pm 7.59^{*}$ & $21.32 \pm 5.65^{*}$ & $6.79 \pm 0.32^{*}$ & $30.75 \pm 1.81^{*}$ \\
\hline & $\mathrm{T}$ & $62.38 \pm 5.01^{*}$ & $14.76 \pm 2.37^{* \#}$ & $4.71 \pm 0.25^{* \#}$ & $26.85 \pm 0.97^{*}$ \\
\hline
\end{tabular}

Mean \pm SD data were from non-diabetic control groups $(\mathrm{N})$, diabetic groups (D), Valsartan treated group $(\mathrm{T})$

${ }^{*} P<0.01$ vs. non-diabetic control group in the same period

${ }^{\#} P<0.01$ vs. diabetic group in the same period

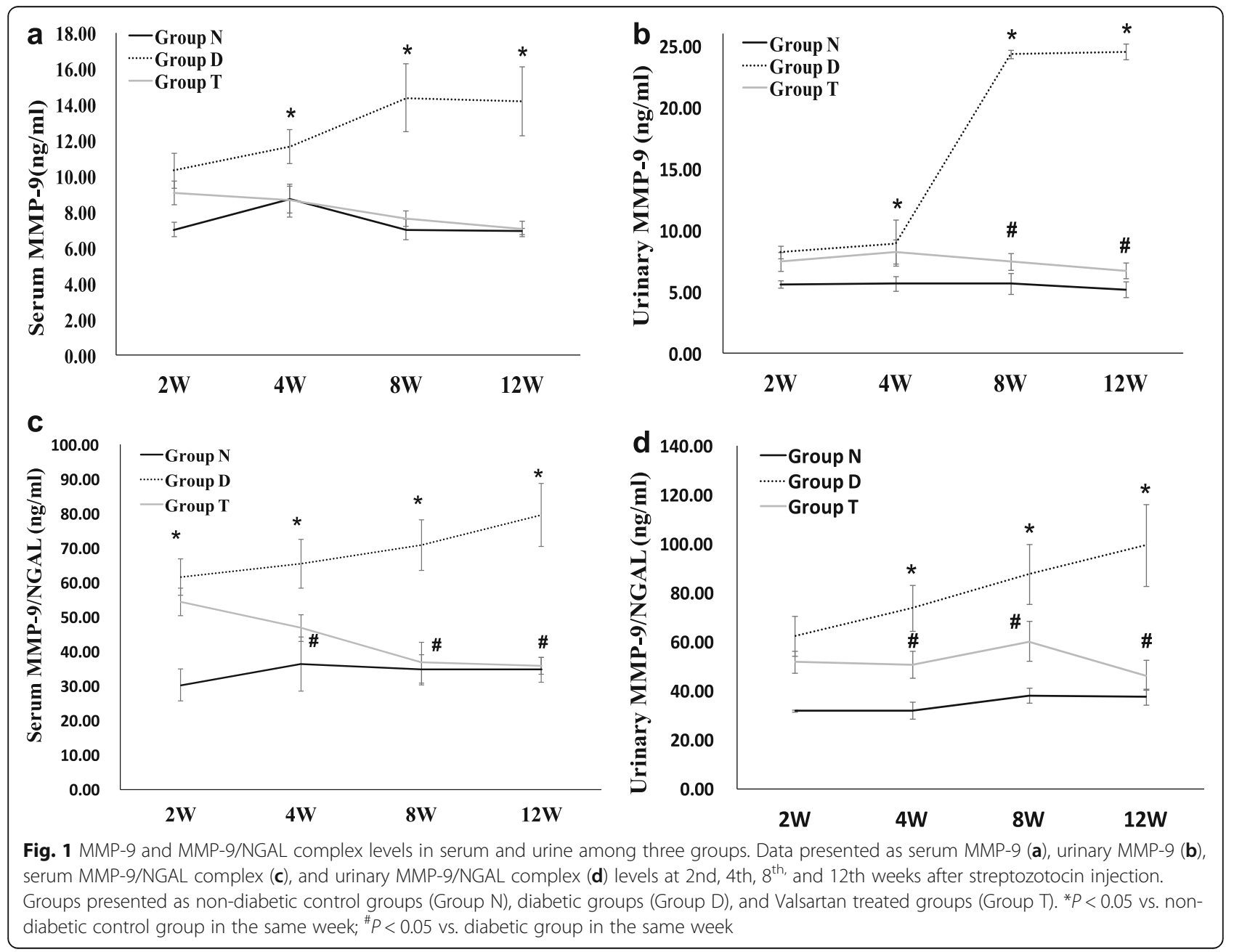



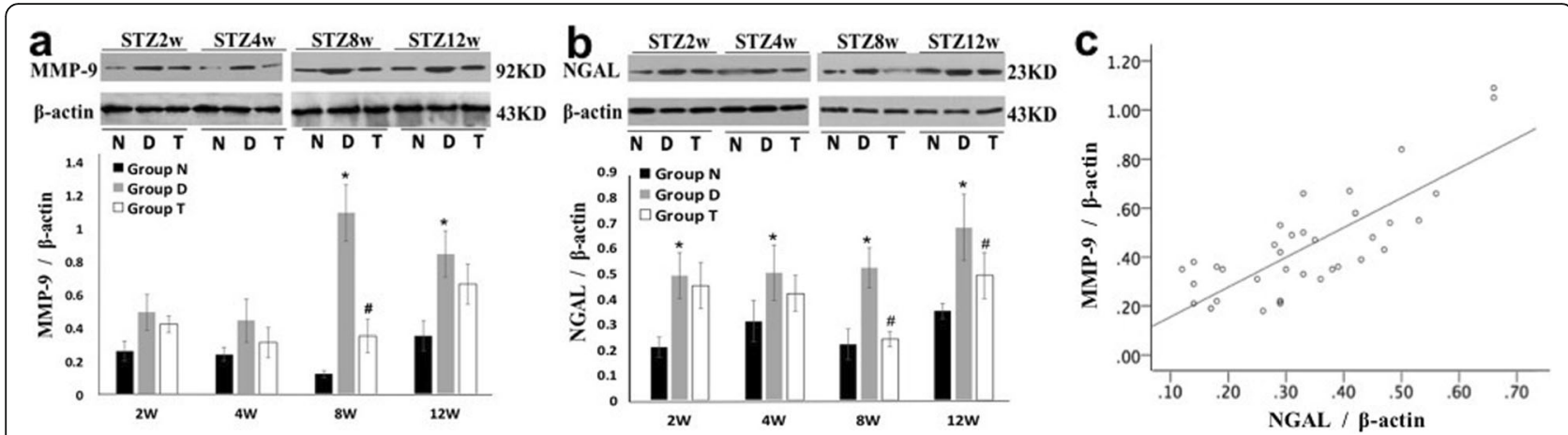

Fig. 2 MMP-9 and NGAL protein expression in the renal medulla of diabetic rats. $\mathbf{a}, \mathbf{b}$ The protein expression and semi-quantitative results of MMP-9 and NGAL. Three groups showed as non-diabetic control groups (Group N), diabetic groups (Group D), and Valsartan treated groups

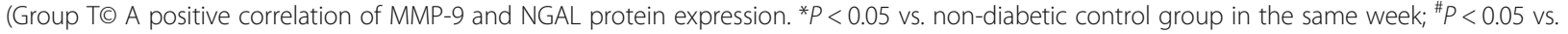
diabetic group in the same week

expression in Fig. 2c yielded a statistically-significant correlation of $0.78(p<0.05)$.

\section{Gene expression of MMP-9, NGAL, and correlation analysis}

Next, Real-time PCR was used to examine the expression of MMP-9 mRNA. Since the end of 2nd week, the mRNA expression for both NGAL (Fig. 3a) and MMP-9 (Fig. 3b) was elevated $(P<0.001)$ compared with non-diabetic controls (Fig. $3 a$ and b, respectively). After treatment with Valsartan, gene expression of MMP-9 was significantly decreased at the end of 4th week, while gene expression of NGAL showed an obvious decrease at the end of 12th week (Fig. 1a and b, respectively). Correlation analysis of MMP-9 and NGAL gene expression in Fig. 3c yielded a statistically-significant correlation of 0.61 $(p<0.05)$.

\section{Histological examinations}

MMP-9 and NGAL expression in the proximal tubular epithelial cells at the 12th week of the study were examined by immunohistochemical staining and semiquantitative analysis. Compared to a non-diabetic group, strong staining of MMP-9 and NGAL were found in the diabetic group. Contrary, the MMP-9, and NGAL staining were decreased in the Valsartan treatment group compared to the diabetic group. Consistently, semiquantitative analysis revealed significant differences between every two groups $(P<0.05$, shown in Fig. 4).

\section{Discussion}

At the moment, available data on the expression of MMP9 in diabetic kidneys remain conflicting. Szu-yuan et al. reported that MMP-9 was significantly increased in the glomeruli of diabetic mice. The same author reported that MMP-9 deficiency could attenuate diabetic renal injury by modulating podocyte functions and dedifferentiation [13].
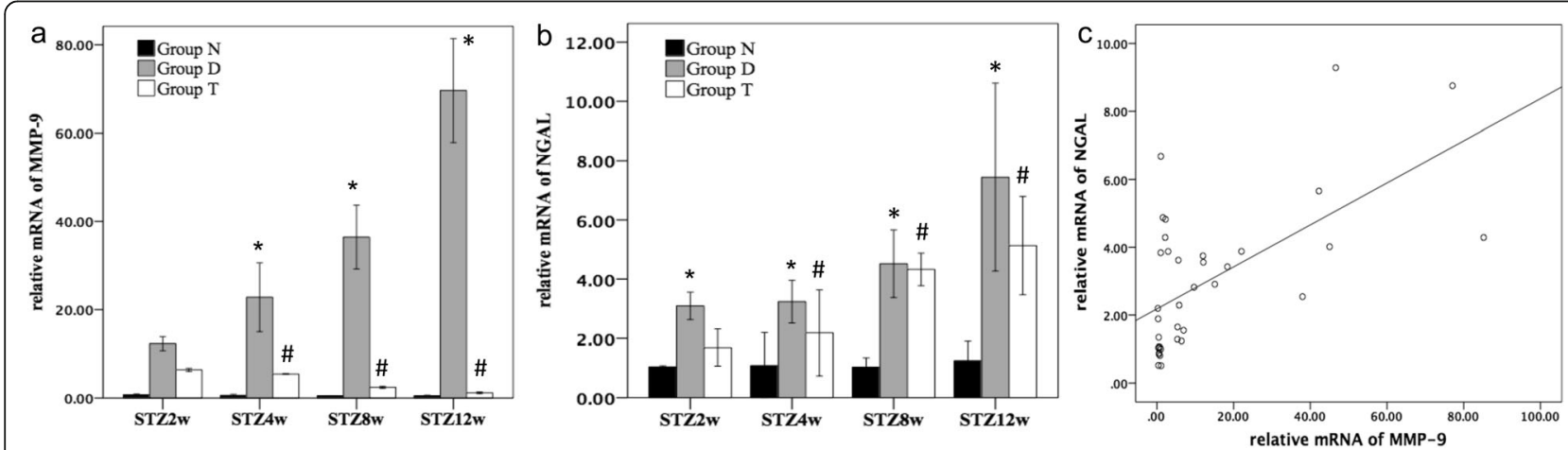

Fig. 3 MMP-9 and NGAL mRNA expression in rats' renal medulla in group N (non-diabetic control), group D (Streptozotocin-induced diabetic rats), and group T (Valsartan $10 \mathrm{mg} \cdot \mathrm{kg}^{-1} \cdot \mathrm{d}^{-1}$ treated) rats. $\mathbf{a}$, b Relative MMP-9 mRNA and NGAL mRNA expression in Groups N, D, and T, normalized against that of glyceraldehyde-3-phosphate dehydrogenase (GAPDH). c A positive correlation of MMP-9 and NGAL gene expression. Data are the mean \pm SD ( $n=8$ in each group). ${ }^{*} P<0.05$ compared with Group N; ${ }^{\#} P<0.05$ compared with Group D 

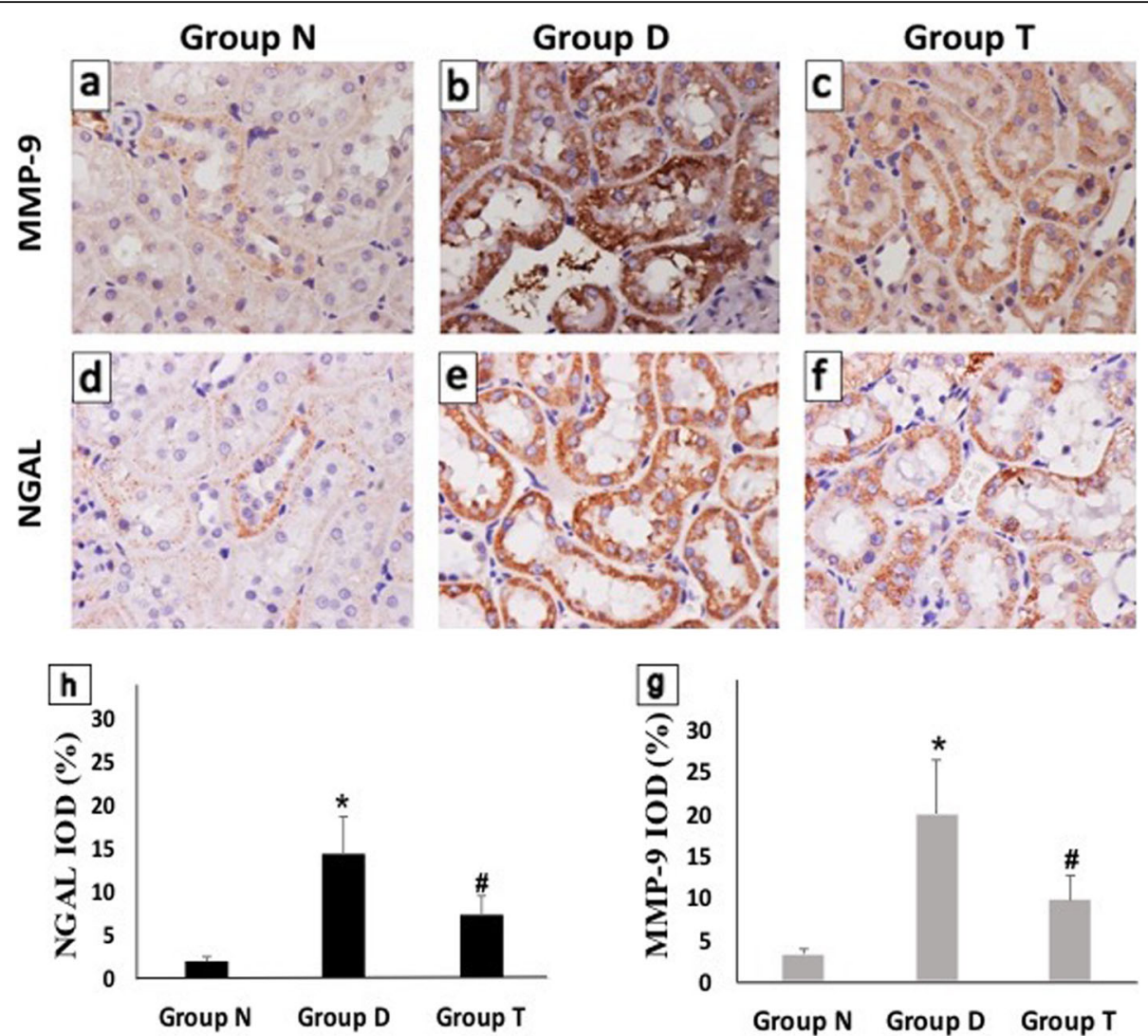

Fig. $4 \mathrm{Imm}$ unohistochemical stain of epithelial cells of proximal renal tubules at the 12th week in each group of rats at magnifications 1,200x under a microscope. a, $\mathbf{d}$ Non-diabetic control group (Group N); b, e diabetic group (Group D); c, $\mathbf{f}$ Valsartan treated group (Group T). $\mathbf{g}, \mathbf{h}$ Semiquantitative analysis of MMP-9 $(\mathbf{g})$ and NGAL (h). Data were expressed as $\%$. ${ }^{*} P<0.05$ compared with Group N; ${ }^{\#} P<0.05$ compared with Group D

However, other studies found a decrease in MMP-9 expression in diabetic rat renal tissue [14-16]. Yet, the expression of MMP-9 on renal tubular epithelial cells in diabetes mellitus remains unclear. In our study, elevated MMP-9 expression was observed in serum, urine, and renal tissues of diabetic rats. The follow-up observation showed a continuation of an uptrend with the aggravation of the renal injury. Furthermore, diabetic rats exhibited increased MMP-9 staining in proximal renal tubular epithelial cells. This inconsistent result may be attributed to the location where MMP-9 is expressed. It has been confirmed that in mice models, MMP-9 was mainly expressed in collecting duct cells and then in proximal tubule epithelial cells and podocytes [17]. Different expression sites were observed in the above studies, resulting in different observation results. Chen et al. [18] have shown that endocytosis of albumin could stimulate MMP-9 secretion by renal tubule epithelial cells under diabetic conditions in vitro, which is consistent with our data. In addition, some researchers suggested biphasic modulation of MMP-9 in the development of diabetic kidney damage [19]. Future studies are needed to further address these issues.
The specific mechanism of MMP-9 involved in the development of diabetic nephropathy is not fully understood. Existing studies have mainly focused on the regulation of MMP-9 on the accumulation of ECM in the glomerulus of diabetic rats, assuming that the abnormal expression of MMP-9 could lead to aberrant ECM degradation and accumulation. In our study, the expression level of MMP-9 in renal tubular epithelial cells in the diabetic group gradually increased with the disease's progression, suggesting that MMP-9 may be involved in the pathogenesis of diabetic renal injury through other mechanisms. Renal fibrosis has been proved to be one of the crucial pathogenesis of DM, including glomerulosclerosis, interstitial fibrosis, tubular atrophy, and other manifestations. Recently, it has been reported that dysregulated MMP-9 may relate to the pathogenesis of renal fibrosis. Tsai et al. have noted that an increased MMP-9 expression in human atrophic tubular nuclear was associated with a greater interstitial fibrosis score $(r=0.40, p=0.002)$, thus suggesting it may have a role in the process of renal injury or fibrosis [20]. Furthermore, Tan et al. have proved a pro-fibrotic role of MMP-9 in tubular cell EMT, and confirmed the pathogenesis of 
MMP-9 involvement in renal fibrosis through recruitment of osteopontin cleavage [4]. Similarly, Ling et al. reported that abnormal expression of MMP-9 was correlated with EMT in podocytes of diabetic rats [21]. More in-depth studies are needed to further explore the pathogenesis of MMP-9 in the process of diabetic kidney injury.

A previous study found that NGAL, a protein that is recognized as a marker of diabetic tubular injury, is abundantly present in diabetic rats [1], which is consistent with our findings. NGAL can form the MMP-9/NGAL complex by binding to MMP-9 [22, 23]. The biological activity of MMP-9 could be prolonged by combination with NGAL through preventing its degradation. In our study, the MMP-9/NGAL complex displayed increased expression in the serum and urine of diabetic rats. In addition, we further investigated the association between NGAL and MMP9 gene and protein expression. A positive correlation was found between the two variables at both the gene and protein levels. NGAL's ability to form this complex seems to be less specific since it has been observed in the serum of patients with malignant tumors [24].

Previous studies reported that Valsartan, which belongs to a kind of angiotensin II receptor blocker (ARB), has renoprotective effects in DN $[25,26]$. However, limited evidence exists on the effect of Valsartan on MMP-9 expression in diabetes. In our research, diabetic rats exhibited significantly increased levels of serum and urinary MMP-9, NGAL, and MMP-9/NGAL complex. An increase in MMP9 expression was prevented by Valsartan treatment 4 weeks after injection of STZ. Further experiments revealed a marked decrease of MMP-9 expression in the treatment group compared with a diabetic group from week 4. Besides, histologically, Valsartan obviously reduced renal proximal tubular injury at the 12th week of the study. The above results suggest that Valsartan could inhibit MMP-9 expression and alleviate the damage of renal tubular damage in STZ-induced diabetic rats. Interestingly, another experiment conducted in diabetic rats showed that Valsartan could block the upregulation of TIMP-1, a natural inhibitor of MMP9, thus preventing the progress of renal interstitial fibrosis [27]. Previous studies have shown that in the process of renal fibrosis, the expression of MMP-9 and TIMP-1 were both increased, which resulted in an imbalanced/decreased MMP-9/TIMP-1 ratio and led to reduced capacity of MMP-9 to degrade ECM. Therefore, ARBs may be involved in the progression of diabetic renal fibrosis by regulating pro-fibrotic factors [28].

\section{Conclusions}

The expression of MMP-9 was significantly increased in diabetic renal tubular epithelial cells. Besides, a positive correlation was found between MMP-9 and NGAL expression, along with high levels of MMP-9/NGAL complex. Valsartan were able to improve above alternations.

\section{Abbreviations}

MMP-9: Matrix metalloproteinases-9; NGAL: Neutrophil gelatinase-associated lipocalin; DN: Diabetic nephropathy; MMPs: Matrix metalloproteinases; ECM: Extracellular matrix; EMT: Epithelial-mesenchymal transformation; TIMPs: Tissue inhibitors of metalloproteinases; Scr: Serum creatinine; BUN: Blood urea nitrogen; UAER: Urinary albumin excretion rate.; sMMP9: Serum MMP-9; uMMP-9: Urinary MMP-9; sNGAL: Serum NGAL; UNGAL: Urinary NGAL; ARB: Angiotensin II receptor blocker

\section{Acknowledgements}

Not applicable.

\section{Statement}

We declare this study was carried out in compliance with the ARRIVE guidelines.

\section{Authors' contributions}

Haiping Chen and Huayu Yang conceived and designed the study. Huayu Yang and Fenghua Liu performed the experiments. Huayu Yang wrote the paper. Haiping Chen and Qing Ma reviewed and edited the manuscript. All authors read and approved the final manuscript.

\section{Funding}

This work was supported by Beijing Friendship Hospital affiliated to Capital Medical University matching funding projects. The study on effects of hyperglycemia on the injury mechanism of renal tubular epithelial cells induced by macrophages.

\section{Availability of data and materials}

The datasets used or analyzed during the current study are available from the corresponding author on reasonable request.

\section{Declarations}

\section{Ethics approval and consent to participate}

The protocol used in this study was approved by the Institutional Review Board of Beijing Friendship Hospital Affiliated to Capital Medical University. All methods were carried out in accordance with relevant guidelines and regulations or under the declaration of Helsinki.

\section{Competing interests}

The authors declare that they have no competing interests.

\section{Author details}

${ }^{1}$ Division of Geriatrics, Medical and Health Care Center, Beijing Friendship Hospital, Capital Medical University, No. 95, Yong'an Road, Xicheng District, 100050 Beijing, People's Republic of China. ²Department of Nephrology, Emergency General Hospital, Beijing, People's Republic of China.

Received: 10 November 2020 Accepted: 5 May 2021

Published online: 03 June 2021

\section{References}

1. Liu F, Yang H, Chen H, Zhang M, Ma Q. High expression of neutrophil gelatinase-associated lipocalin (NGAL) in the kidney proximal tubules of diabetic rats. Adv Med Sci. 2015:60(1):133-38.

2. Tsioufis C, Bafakis I, Kasiakogias A, Stefanadis C. The role of matrix metalloproteinases in diabetes mellitus. Curr Top Med Chem. 2012;12 (10): 1159-65.

3. Kolset SO, Reinholt FP, and Jenssen T. Diabetic nephropathy and extracellular matrix. J Histochem Cytochem. 2012;60 (12), 976-86.

4. Tan TK, Zheng G, Hsu TT, Lee SR, Zhang J, Zhao Y, et al. Matrix metalloproteinase- 9 of tubular and macrophage origin contributes to the 
pathogenesis of renal fibrosis via macrophage recruitment through osteopontin cleavage. Lab Invest. 2013;93(4):434-49.

5. Yang J, Shultz RW, Mars WM, Wegner RE, Li Y, Dai C, et al. Disruption of tissue type plasminogen activator gene in mice reduces renal interstitial fibrosis in obstructive nephropathy. J Clin Invest. 2002;110 (10):1525-38.

6. Wang $X$, Zhou $Y$, Tan $R$, Xiong $M$, He W, Fang $L$, et al. Mice lacking the matrix metalloproteinase- 9 gene reduce renal interstitial fibrosis in obstructive nephropathy. Am J Physiol Renal Physiol. 2010;299(5): F973-82.

7. Chan PS, Kanwar M, Kowluru RA. Resistance of retinal inflammatory mediators to suppress after reinstitution of good glycemic control: novel mechanism for metabolic memory. J Diabetes Complications. 2010;24(1):55-63.

8. Kiaei M, Kipiani K, Calingasan NY, Wille E, Chen J, Heissig B. Matrix metalloproteinase-9 regulates TNF-alpha and FasL expression in neuronal, glial cells and its absence extends life in a transgenic mouse model of amyotrophic lateral sclerosis. Exp Neurol. 2007;205(1):74-81.

9. Leclercq A, Houard X, Philippe M, Ollivier V, Sebbag U, Meilhac O, et al. Involvement of intraplaque hemorrhage in atherothrombosis evolution via neutrophil protease enrichment. J Leukoc Biol. 2007;82: 1420-29.

10. Yan L, Borregaard N, Kjeldsen L, Moses MA. The high molecular weight urinary matrix metalloproteinase (MMP) activity is a complex of gelatinase B/MMP-9 and neutrophil gelatinase-associated lipocalin (NGAL). Modulation of MMP-9 activity by NGAL. J Biol Chem. 2001;276: 37258-65.

11. Rincon-Choles H, Kasinath BS, Gorin Y, Abboud HE. Angiotensin II and growth factors in the pathogenesis of diabetic nephropathy. Kidney Int Suppl. 2002:82:S8-11.

12. Andersen S. Angiotensin II receptor blockade in diabetic nephropathy. Dan Med Bull. 2004; 51:274-94.

13. Li SY, Huang PH, Yang AH, Tarng DC, Yang WC, Lin CC, et al. Matrix metalloproteinase-9 deficiency attenuates diabetic nephropathy by modulation of podocyte functions and dedifferentiation. Kidney Int. 2014; 86(2): 358-69.

14. Yao XM, Ye SD, Zai Z, Chen Y, Li XC, Yang GW, et al. Simvastatin protects diabetic rats against kidney injury through the suppression of renal matrix metalloproteinase-9 expression. J Endocrinol Invest. 2010;33(5): 292-96.

15. McLennan SV, Kelly DJ, Cox AJ, Cao Z, Lyons JG, Yue DK, et al. Decreased matrix degradation in diabetic nephropathy: effects of ACE inhibition on the expression and activities of matrix metalloproteinases. Diabetologia 2002;45(2): 268-75.

16. Tripathi YB, Shukla R, Pandey N, Pandey V, Kumar M. An extract of Pueraria tuberosa tubers attenuates diabetic nephropathy by upregulating matrix metalloproteinase-9 expression in the kidney of diabetic rats. J Diabetes. 2017; 9(2):123-132

17. Legallicier B, Trugnan G, Murphy G, Lelongt B, Ronco P. Expression of the type IV collagenase system during mouse kidney development and tubule segmentation. J Am Soc Nephrol. 2001;12(11):2358-69.

18. Chen X, Cobbs A, George J, Chima A, Tuyishime F, Zhao X. Endocytosis of Albumin Induces Matrix Metalloproteinase-9 by Activating the ERK Signaling Pathway in Renal Tubule Epithelial Cells. Int J Mol Sci. 2017;18(8):1758.

19. Xu X, Xiao L, Xiao P, Yang S, Chen G, Liu F, et al. A glimpse of matrix metalloproteinases in diabetic nephropathy. Curr Med Chem. 2014;21(28): 3244-60.

20. Tsai JP, Liou JH, Kao WT, Wang SC, Lian JD, Chang HR. Increased expression of intranuclear matrix metalloproteinase 9 in atrophic renal tubules is associated with renal fibrosis. PLoS One. 2012;7(10): e48164.

21. Ling L, Chen L, Zhang C, Gui S, Zhao H, Li Z. High glucose induces podocyte epithelialtomesenchymal transition by demethylationmediated enhancement of MMP9 expression. Mol Med Rep. 2018;17(4):5642-51.

22. Cakirca G, Turgut FH. Serum Matrix Metalloproteinase-9, Tissue Inhibitor of Metalloproteinase-1 and Matrix Metalloproteinase-9/ Neutrophil Gelatinaseassociated Lipocalin Complex Levels in Patients With Early-stage Diabetic Nephropathy. Iran J Kidney Dis. 2018;12(5):299-304.

23. Rood KM, Buhimschi IA, Rodewald Millen K, Bahtiyar MO, Thung S, Summerfield T, et al. Evidence for participation of neutrophil gelatinaseassociated lipocalin/matrix metalloproteinase-9 (NGAL-MMP-9) complex in the inflammatory response to infection in pregnancies complicated by preterm birth. Am J Reprod Immunol. 2016;76(2):108-117.

24. Cymbaluk-Płoska A, Chudecka-Głaz A, Pius-Sadowska E, Sompolska-Rzechuła A, Chudecka K, Bulsa M, Machaliński B, et al. Clinical Relevance of NGAL/ MMP-9 Pathway in Patients with Endometrial Cancer. Dis Markers. 2017; 2017:6589262.
25. Makary S, Abdo M, Hassan WA, Tawfik MK. Angiotensin blockade attenuates diabetic nephropathy in hypogonadal adult male rats. Can J Physiol Pharmacol. 2019;97(8):708-20.

26. Uijl E, 't Hart DC, Roksnoer LCW, Groningen MCC, van Veghel R, Garrelds IM, et al. Angiotensin-neprilysin inhibition confers renoprotection in rats with diabetes and hypertension by limiting podocyte injury. J Hypertens. 2020; 38(4): 755-64.

27. Tang L, Yi R, Yang B, Li H, Chen Liu. Valsartan inhibited HIF-1a pathway and attenuated renal interstitial fibrosis in streptozotocin-diabetic rats. Diabetes Research and Clinical Practice. 2012;97(1):125-131.

28. Duymelinck C, Deng JT, Dauwe SE, De Broe ME, Verpooten GA. Inhibition of the matrix metalloproteinase system in a rat model of chronic cyclosporine nephropathy. Kidney Int.1998;54(3): 804-18.

\section{Publisher's Note}

Springer Nature remains neutral with regard to jurisdictional claims in published maps and institutional affiliations.
Ready to submit your research? Choose BMC and benefit from:

- fast, convenient online submission

- thorough peer review by experienced researchers in your field

- rapid publication on acceptance

- support for research data, including large and complex data types

- gold Open Access which fosters wider collaboration and increased citations

- maximum visibility for your research: over $100 \mathrm{M}$ website views per year

At BMC, research is always in progress.

Learn more biomedcentral.com/submissions 